\title{
КЛАСТЕРНЫЕ ТЕХНОЛОГИИ В ПАРАДИГМЕ РАЗВИТИЯ РЕГИОНАЛЬНЫХ ИННОВАЦИОННЫХ СИСТЕМ (ОКОНЧАНИЕ) *
}

\author{
(C) 2018 Коновалова Мария Евгеньевна \\ доктор экономических наук, заведующая кафедрой экономической теории \\ Самарский государственный экономический университет \\ 443090, г. Самара, ул. Советской Армии, 141 \\ E-mail:mkonoval@mail.ru \\ (c) 2018 Кузьмина Ольга Юрьевна \\ кандидат экономических наук, доцент кафедры экономической теории \\ Самарский государственный экономический университет \\ 443090, г. Самара, ул. Советской Армии, 141 \\ E-mail: pisakina83@yandex.ru, \\ (C) 2018 Хансевяров Рустам Идрисович \\ доктор экономических наук, профессор кафедры экономической теории \\ Самарский государственный экономический университет \\ 443090, г. Самара, ул. Советской Армии, 141 \\ E-mail: rust1978@mail.ru
}

В статье рассмотрены вопросы, отражающие проблематику формирования и развития региональной инновационной системы в ее тесном взаимодействии с кластерной политикой региона и его интеллектуальным потенциалом, показан механизм создания эффективных территориальных структурных образований, предполагающих активное взаимодействие государства и частного бизнеса, сделан вывод о необходимости стимулирования институтов регионального развития с целью создания условий для инноваций.

Ключевые слова: кластерные технологии, региональные инновационные системы, кластеры, инновации, региональный институт развития

Использование кластерных технологий в парадигме развития региональных инновационных систем имеет под собой объективную основу, поскольку:

- способствует повышению эффективности деятельности предприятий, входящих в состав кластера;

- создает предпосылки усиления инновационной активности.

Для предприятий участие в кластере предоставляет определенные преимущества в доступе к новым технологиям, сырью, методам работы и возможностям организациям поставок. Предприятия, входящие в кластер, значительно быстрее узнают о новых концепциях в обслуживании и маркетинге, о доступности новых видов сырья и оборудования, о прогрессе технологий, поскольку решение этих задач значительно облегчаются постоянными взаимодействиями с другими участниками кластера. Функциони- рование предприятий в кластере обеспечивает возможность непосредственного прямого наблюдения за деятельностью других фирм. В то время как отдельно работающие, изолированные предприятия имеют меньший доступ $\mathrm{k}$ информации, что обусловливает более высокие издержки. Кроме того, для предприятий, не входящих в кластеры возрастает необходимость в выделении соответствующих ресурсов на получение новой информации в пределах своей собственной структуры.

Весьма актуальны и экономически значимы потенциальные преимущества кластеров в создании условий для инноваций. Очень часто предприятие - участник кластера - может гораздо быстрее осуществлять поиск источников для новых компонентов, услуг, оборудования, а также других требуемых при введении инноваций элементов, таких как новая технология или новая производственная линия, модернизиро-

\footnotetext{
* Исследование выполнено при финансовой поддержке РФФИ и Правительства Самарской области в рамках научного проекта № 18-410-630003
} 
ванный процесс или передовая модель снабжения и поставок. Находящиеся в составе кластера местные поставщики и партнеры оказываются вовлеченными в процесс модернизации и обновления, и этим обеспечивается лучшее соответствие поставляемой ими продукции потребностям предприятий. Кроме того, качественно новый специализированный персонал для реализации возникающих при использовании новых подходов специальных профессиональных качеств легче набрать непосредственно в данной местности. Входящие в кластер предприятия могут не брать на себя больших обязательств до тех пор, пока окончательно не удостоверятся в том, что инновация (новое изделие, процесс или услуга) будут обеспечивать необходимый экономический эффект, что позволяет им экспериментировать при меньших издержках.

Предприятия, полагающиеся на автономную интеграцию по вертикали, дополнительно сталкиваются с инерцией: сложности в торговле. Связанные с инновациями снижают ценность внутренних капиталовложений; при этом возникает необходимость поддержания существующей продукции и процессов во время развития новых. Устойчивое развитие является важным конкурентным преимуществом экономической системы. В связи с этим кластеры, повышая конкурентоспособность региона, могут в значительной степени влиять на устойчивое развитие экономики страны в целом.

Определяющее значение в формировании и эффективном развитии кластеров оказывает инновационный фактор, а именно волновая теория инноваций. Цикличность представляет собой ярко выраженную закономерность развития системы. Циклическому развитию подвержено и внедрение новых технологий в промышленности, что способствует переходу экономической системы на новый этап развития.

Теория кластеров М. Портера основана на том, что наиболее конкурентоспособные в международных масштабах фирмы одной отрасли обычно сконцентрированы в конкретном регионе, что связано с волновой природой инноваций, распространяющих вокруг себя наиболее конкурентоспособные компании и затрагивающие поставщиков, потребителей и других контрагентов [1].

Основой закрепления позитивных результатов и дальнейшего экономического роста путем повышения конкурентоспособности региона должен стать новый «портфель ресурсов», основу которого составляю такие элементы как:

- мобильная рабочая сила, владеющая ключевыми навыками и компетенциями;

- производительные инновационно-информационные технологии;

- правовая, транспортно-коммуникационная и торговая интеграция в большие открытые внешние рынки;

- контроль конкурентных рыночных позиций на внутренних рынках.

В качестве основой целевой установки реализации стратегии устойчивого развития региона является наращивание воспроизводственного потенциала территорий на основе формирования нового портфеля ресурсов для повышения конкурентоспособности производящих секторов экономики, осуществляющих выпуск продукции с высокой добавленной стоимостью, средне и высокотехнологичных видов продукции и услуг; расширенного воспроизводства человеческих и природных ресурсов [2].

В настоящее время первичный потенциал импортозамещения реализован на $70 \%$, что говорит о том, что кластерная сеть может расширяться только низкими темпами за счет еще незадействованных позиций в импортозамещении, то есть пересмотра договоров корпораций в пользу местных производителей [3]. Еще один способ развития кластерной сети связан с реализацией программы аутсорсинга, которая экстенсивно расширит возможности кластерной сети по производству продукции для корпораций и для внешнего потребления. Если передать некоторые подразделения корпораций в управление отечественным производителям, то это увеличит их объемы производства и дать возможность реализации стратегии развития, также можно использовать проект индустриального парка в целях стимулирования развития кластерных сетей. Стратегическими приоритетами кластера являются рост:

- производительности труда;

- рентабельности предприятий;

- занятости населения;

- расширения номенклатуры продукции промышленного производства;

- уровня переработки сырья;

- экспортного потенциала области;

- развития смежных отраслей экономики.

Существующие проблемы кластера можно разделить на внешние и внутренние. К внутрен- 
ним проблемам по степени их значимости можно отнести следующие позиции:

Кадры. Ощущается недостаток в квалифицированных рабочих специальностях машиностроения, а также в менеджерах управления.

Сырье и материалы. Используемые на многих предприятиях машиностроения и металлургии сырье и материалы завозятся из других стран.

Фискальная политика и доступность денежных средств. Основной проблемой для участников кластера является ценообразование на внутреннем рынке.

Научно-техническое обеспечение. В настоящее время на большинстве предприятий коэффициент износа оборудования составляет 40-60\%. Модернизация и реконструкция предприятий не требует замены существующих технологий и оборудования, но для этого нет достаточной информации о передовых технологиях, ноу-хау и оборудовании. Для развития предприятий необходимо укрепить связь науки с производством и осуществлять трансфер технологий и оборудования.

Инфраструктура. Помимо развития крупных предприятий - участников кластера - важно создание сети предприятий мелкого и среднего бизнеса в сфере обслуживания производства, ремонта, организации новых производств.

Маркетинг. Отсутствуют квалифицированные маркетинговые службы и маркетологи, что очень важно для последующего развития кластеров.

Важнейшим элементом кластерного принципа развития региона является установление стабильных связей между всеми его участниками: малых и крупных предприятий, соответствующих органов власти, инфраструктурных и научно-исследовательских организаций, системы профессионального образования.

Для бизнеса кластер - это реальная возможность обеспечить себе конкурентоспособность в будущем. Кластеры, как и любая другая привлекательная методика, могут принести результаты только тогда, когда они вписаны в более широкий контекст стратегии развития. Они могут создаваться двумя путями: спонтанно (без непосредственной государственной поддержки) и по инициативе государства - искусственные кластеры.

При проведении макроэкономической политики, стимулирующей конкурентоспособность, важнейшей задачей науки и практического менеджмента должна стать разработка соответствующих рекомендаций и устранение препятствий для роста возникающих кластеров в РФ.

Национальная экономика оценивается по таким индексам как бизнес-климат, способность предприятий к инновациям, индекс восприятия коррупции и др.

Интересен как позитивный, так и негативный опыт повышения конкурентоспособности, причем как страновой, так и региональной. Должно быть общее видение того, как повысить уровень конкурентоспособности со всеми вытекающими отсюда последствиями - новая прибыль, усиление кадрового потенциала, которые станут ядром нового экономического центра, имеющего первоначально региональное значение, но с возможностями выхода на мировой уровень. Если в некоторых отраслях таких как, например, туризм формирование кластеров происходит относительно быстро, то в других сферах подобные процессы требуют значительно большего временного отрезка [4]. Так, например, существуют определенные проблемы в металлургии, а также производстве строительных материалов. Металлургическая отрасль представлена крупными компаниями, обладающими собственными стратегиями в отношении добычи ресурсов. В производстве стройматериалов другая сложность - слишком много компаний и товарных позиций. В каждом регионе есть аналогичные компании и большинство из них работают в теневом секторе. Основной причиной отсутствия инициатив на кластерных встречах является то, что компании пока не видят для себя выгоды от работы в кластерах. Кроме того, не везде кластерную инициативу воспринимают позитивно. Так как существует много различных методов и подходов, способных повлиять на конкурентоспособность. Тем не менее, кластерное развитие на практике зарекомендовало себя во всем мире, лучшие бренды, лучший бизнес в мире происходили, так или иначе, через кластерную стадию. Часть этих кластеров создавалось традиционно в процессе эволюции, некоторые кластеры особенно в последние 20 лет были созданы путем дополнительно стимулирования, катализатором которого чаще всего выступало правительство, которое мотивировало бизнес думать по новому, но не административными методами, а экономическими.

Таким образом, мировой опыт развития 
кластеров свидетельствует: кластерная структуризация экономики оказывает существенное влияние на общую экономическую политику государства, прежде всего это связано с поддержкой науки, рискованных инноваций, экспортной деятельностью, созданию необходимой инфраструктуры и образования. Во многих организациях, объединенных кластерными технологиями, все большая часть экономического эффекта достигается в результате применения специальных знаний, широкого обучения персонала и взаимодействия с партнерами и контрагентами. Политика, опирающаяся на развитие кластеров, ведет к повышению конкурентоспособности государства. Создание кластеров обеспечивает новые возможности для бизнеса, приводит к повышению устойчивости развития малого предпринимательства, возрастанию экологической ответственности предприятий, расширению границ их инициативной природоохранной деятельности.

\section{Библиографический список}

1. Портер М. Конкуренция/ Перевод с англ.Москва. 2002. С. 234.

2. Матвеев Ю.В., Коновалова М.Е. Институциональная структура и ее роль в сбалансированности общественного воспроизводства// Фундаментальные исследования. 2009. № 3-S. С. 90.

3. Вальтер Ж. Конкурентоспособность: общий подход. Москва. 2017. С. 52.

4. Куренков Ю. Концепция конкурентоспособности и ее эволюция. Конкурентоспособность России в мировой экономике// Вопросы экономики. 2001. № 6. С. 36-50.

Поступила в редакцию 14.08.2018 